\title{
Fostering aspects of religion, education, and skills for adolescents in Tebas Sungai Sambas Regency
}

\author{
M. Mushoddik ${ }^{a, 1}$, Gufron Amirullah ${ }^{b, 2}$, S. Susilo ${ }^{b, 3^{*}}$ \\ ${ }^{a}$ Pendidikan Geografi, Universitas Muhammadiyah Prof. DR. HAMKA, Jalan Tanah Merdeka, Jakarta, Indonesia \\ ${ }^{b}$ Pendidikan Biologi, Universitas Muhammadiyah Prof. DR. HAMKA, Jalan Tanah Merdeka, Jakarta, Indonesia \\ ${ }^{1}$ mushoddikdaulay@uhamka.ac.id; ${ }^{2}$ gufronamirullah@uhamka.ac.id; susilo@uhamka.ac.id \\ * Corresponding author
}

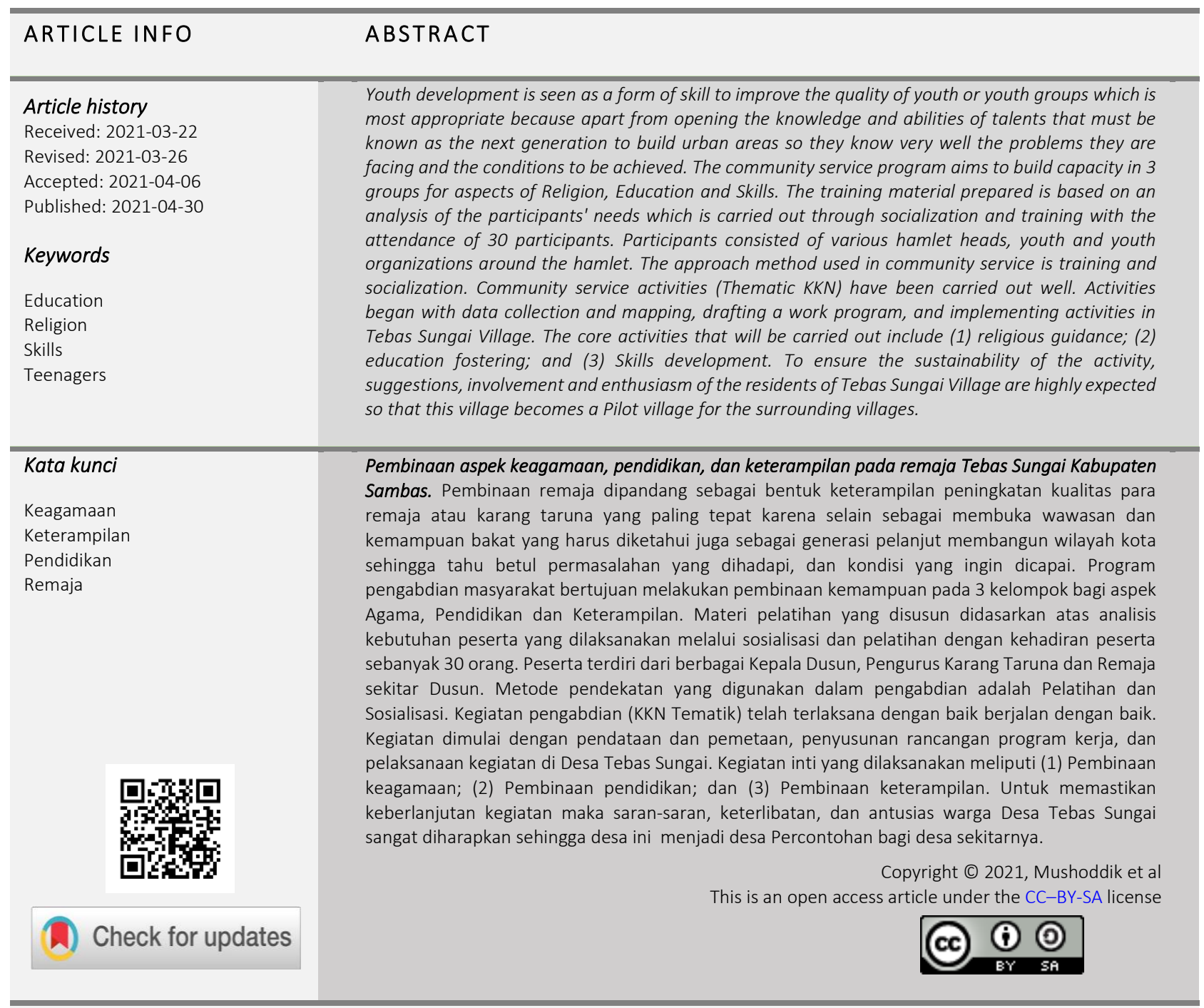

How to cite: Mushoddik, M., Amirullah, G., \& Susilo, S. (2021). Fostering aspects of religion, education, and skills for adolescents in Tebas Sungai Sambas Regency. Journal of Community Service and Empowerment, 2(1), 41-46. https://doi.org/10.22219/jcse.v2i1.16054

\section{PENDAHULUAN}

Potensi peserta didik dapat dikembangkan melalui proses sistematis dan pembiasaan tertentu. Perlu adanya pengertian dan pemahaman pendidik dalam proses pengembangan potensi tersebut. Pengembangan potensi dalam hal kecakapan dan keterampilan mencakup banyak hal (Hatimah, 2003), diantaranya personal skill, social skill, academic skill, dan 
vocational skill. Pendidik artinya bersedia mendidik dan membangun karakter peserta didik. Kegiatan pendidikan pada tahap melatih, akan berfokus pada kemampuan motorik peserta didik (Mulyasa, 2002). Kemampuan motorik dilatih melalui pembiasaan dan mengkondisikan peserta didik untuk berpikir kritis, strategis, dan taktis dalam pembelajaran (Atik, 2019). Melalui metode ilmiah beberapa aspek kemampuan peserta didik dapat dikembangkan dengan baik. Langkah-langkah dan pemahaman dari metode dalam pembinaan dapat dijadikan pedoman dalam menyempurnakan kegiatan pembelajaran agar terfokus pada keterampilan dan kecakapan siswa.

Pemberdayaan seluruh perangkat pembelajaran diperlukan dalam pengembangan potensi peserta didik. Pendidik berperan dalam mengantarkan peserta didik mengenali diri dan potensi yang mereka milik (Sari et al., 2018)i. Strategi pembelajaran berperan dalam melatih integritas peserta didik dalam menyelesaikan masalah (Fajriah, 2017). Lingkungan belajar menjadi tempat berlatih sosialisasi, baik kepada teman sebaya, orang tua, (Chen, 2005)bahkan kepada alam semesta. Peran orang tua di rumah juga diperlukan peserta didik dalam mengenali diri dan potensinya (Maghfiroh et al., 2016).

Konsep diri peserta didik merupakan cara pandang yang ada terhadap kemampuan dan potensi pada setiap individu. Melalui pengalaman, interaksi, dan otoritas bagi individu maka konsep diri akan melekat pada pribadi peserta didik (Handayani et al., 2020). Konsep diri akan mempengaruhi cara berpikir, bersikap dan bertindak dalam berbagai hal yang dilakukan. Konsep diri terdiri atas diri ideal, citra diri dan harga diri (Hamner \& Turner, 1990). Selama ini orang selalu menilai seorang remaja berbakat dan pintar hanya dari nilai yang diperoleh di sekolah, sehingga jika seorang remaja mendapatkan nilai yang kurang dengan cepat orang akan mengatakan bahwa si remaja bodoh dan tidak memiliki potensi apa pun (Susana, 2006). Pandangan dan penilaian semacam ini sangat keliru dan menyesatkan. Akibat pandangan keliru itu si remaja tidak dapat mengembangkan dan menemukan potensi yang ada dalam dirinya (Papalia, 2004).

(Gardner \& Knoop, 2009) telah mengembangkan model kecerdasan yang disebut multiple intelligence lebih dari 20 tahun. la tiba pada satu pandangan bahwa kecerdasan bukanlah sesuatu yang bersifat tetap. Kecerdasan akan lebih tepat kalau digambarkan sebagai suatu kumpulan kemampuan atau keterampilan yang dapat ditumbuhkan dan dikembangkan. Kecerdasan bersifat laten, ada di diri tiap manusia tetapi dengan kadar pengembangan yang berbeda (Marsh et al., 2003). Dalam menjelaskan mengenai kecerdasan, ia menggunakan kata 'bakat' atau 'talenta'. Konsep multiple intelligence yang dikembangkannya terdiri atasi delapan jenis kecerdasan, yaitu (1) Kecerdasan linguistik, kemampuan dalam bidang bahasa. (2) Kecerdasan matematika dan logika, kemampuan dalam berpikir abstrak dan terstruktur. (3) Kecerdasan visual dan spasial, kemampuan yang berhubungan dengan gambar, diagram, peta, maupun grafik. (4) Kecerdasan musik, kemampuan yang sangat kreatif dalam hal musik. (5) Kecerdasan interpersonal, mampu bergaul dan beradaptasi dengan cepat, mampu menjadi mediator, dan pintar dalam hal berkomunikasi. (6) Kecerdasan intrapersonal, kemampuan untuk dapat mengerti diri sendiri serta kemampuan untuk memperhatikan nilai dan etika hidup. (7) Kecerdasan kinestetik, ahli dalam hal-hal yang berhubungan dengan fisik, pekerjaan tangan dan dalam hal mengelola suatu objek. (8) Kecerdasan naturalis, kemampuan untuk mencintai alam dan berinteraksi dengan hewan maupun tumbuhan

Pengembangan potensi seorang remaja hendaklah memperhatikan hal-hal tersebut. Meniadakan atau mengesampingkan salah satu aspek di dalamnya merupakan pekerjaan sia- sia dalam usaha menggali potensi seorang remaja (Marsh et al., 2003). Perlu dukungan dari orang tua dan guru dalam mengembangkan potensi yang ada dalam diri seorang remaja sehingga mereka bisa meraih semua impian masa depan mereka (Hagger, M et al., 2005). Bantu mereka agar memiliki konsep diri yang baik dan benar, lihatlah mereka dari sudut pandang multiple intelligence, biarkan mereka berkembang sesuai dengan kecerdasan yang mereka miliki (Henderson, C et al., 2006). Sehubungan dengan itu, program pengabdian masyarakat bertujuan melakukan pembinaan kemampuan pada 3 kelompok bagi aspek Agama, Pendidikan dan Seni.

\section{METODE}

Kegiatan pelatihan ini diikuti oleh remaja karang taruna selama 2 minggu. Pemberi materi atau narasumber adalah 2 orang dosen UHAMKA. Kemudian melibatkan para mahasiswa yang ditempatkan sebagai instruktur. Tempat pelatihan dilaksanakan di 2 tempat Masjid Baiturrahman dan teras rumah warga. Para peserta diantaranya 30 Remaja dan 6 anakanak (usia SD 4-6). Bentuk pelatihannya adalah bersifat 2 arah disertai dengan diskusi, dimana para peserta diminta untuk menunjukkan prestasi atau kemampuan yang dimiliki, kemudian para peserta diarahkan kepada para instruktur untuk diarahkan dalam pembinaan dan membuat kegiatan yang dapat mengasah keterampilan dan kemampuan para peserta. Tim Dosen akan memberikan solusi bagaimana mendapatkan kesulitan yang belum dimiliki dan langkah- langkah apa yang harus dilakukan pihak karang taruna dan instruktur untuk mendapatkan pembinaan yang lebih khusus.

Berdasarkan permasalahan yang diuraikan di atas, maka untuk mengatasi masalah yang dihadapi oleh Karang Taruna, kerangka pemecahan masalah dan solusi yang ditawarkan diuraikan secara ringkas. Permasalahan Remaja dalam pergaulan Era revolusi industri 4.0 dengan menggunakan Pelatihan, Pemetaan, dan pendampingan kemudian akan dilakukan Pelatihan dan pendampingan terkait dalam pengukuran dan kemampuan bakat Remaja (Arief \& Adi, 2014). Pelaksanaan akan menyesuaikan perlengkapan metode dan tempat (Pratama et al., 2018). Khalayak sasaran dalam program pengabdian masyarakat ini adalah Karang Taruna Kecamatan Tebas dusun Tebas Sungai. Sedangkan aplikasi pelaksanaan pengabdi melibatkan 3 mahasiswa sebagai pendamping dan teknis kegiatan di lapangan. 


\section{HASIL DAN PEMBAHASAN}

\section{Pendataan dan pemetaan}

Kegiatan Pengabdian pada Masyarakat dengan nama kegiatan "Merajut Nusantara II" berlangsung dari tanggal $11 \mathrm{~s} / \mathrm{d}$ 20 Maret 2019 yang ditempatkan di Provinsi Kalimantan Barat, Kabupaten Sambas, Kecamatan Tebas yaitu Tebas Sungai. Dalam kegiatan pengabdian masyarakat kali ini, Universitas Muhammadiyah Prof. DR. Hamka mengirimkan dua dosen dan tiga mahasiswa perwakilan dari Fakultas FKIP, Prodi Pendidikan Geografi dan Biologi. Mahasiswa antusias karena ini merupakan hal yang baru bagi mereka diterbangkan ke Provinsi Kalimantan Barat untuk melakukan kegiatan pengabdian masyarakat yang diadakan oleh LLDIKTI (Lembaga Layanan DIKTI) wilayah III. Penempatan pada kegiatan ini terletak di Kecamatan Tebas desa Tebas Sungai, ditugaskan di salah satu Desa yaitu Tebas Sungai. Kelompok 1, yaitu Mushoddik, M.Pd, Rizki, Winda, Fani ditugaskan di Desa Tebas Sungai, Kecamatan Tebas. Penempatan Dosen dan ketiga mahasiswa Universitas Muhammadiyah Prof. DR. Hamka tersebut adalah hasil keputusan panitia yang telah diinformasikan kepada seluruh Dosen dan mahasiswa peserta pengabdian masyarakat.

Sebelum melakukan keberangkatan, dosen dan mahasiswa diberikan perbekalan berupa materi-materi dan informasi seputar situasi tempat Pengabdian masyarakat yang tepat di Provinsi Kalimantan Barat. Pembekalan yang diberikan untuk mahasiswa adalah materi umum yang bersifat teori. Teori-teori tersebut berisikan mengenai hal-hal seputar yang dilakukan dalam melakukan studi lapangan nanti, dengan adanya pembekalan, diharapkan dapat menjadi bekal dalam melaksanakan tugas di lapangan. Tidak hanya teori, dosen dan mahasiswa selanjutnya diberikan ilustrasi tentang lokasi kegiatan Studi Lapangan. Penjelasan tersebut melingkupi tentang keadaan geografis maupun potensi yang ada di daerah tersebut. Dosen dan mahasiswa juga diberikan pretest untuk menilai kesiapan melakukan kegiatan Pengabdian masyarakat serta bimbingan yang diberikan langsung oleh ketua bidang dari setiap bidang yang ada.

Pertemuan kelompok ini dibimbing oleh masing-masing DPL (Dosen Pembimbing Lapangan) yang bertanggung jawab untuk memberikan pengarahan yang akan dilakukan nantinya di lapangan. Pada penutup pembekalan mahasiswa dibagi ke dalam masing-masing program studi untuk diberikan tugas membuat contoh kegiatan yang akan dilakukan di lapangan beserta kebutuhan apa saja yang akan dijadikan bahan pertimbangan dalam kegiatan yang akan berlangsung.

\section{Rancangan program kerja}

Program KKN Tematik Merajut Nusantara II khusus Universitas Muhammadiyah Prof. Dr. Hamka tahun 2019 yang berlokasi di Desa Nibung, dan Desa Tebas Sungai di Kabupaten Sambas, Kalimantan Barat untuk kelompok Bidang Pendidikan dilaksanakan dengan menyusun beberapa kegiatan yang akan dilaksanakan. Bentuk kegiatan yang akan dilaksanakan sesuai data yang diperoleh dari Karang Taruna untuk pemetaan potensi remaja (Gambar 1). Berdasarkan data identifikasi yang diperoleh maka fokus dalam pembinaan Karang Taruna untuk meningkatkan potensi remaja desa, maka kemudian akan dirancang kelompok dan kegiatan pembinaan; baik pemanfaatan fasilitas, motivasi pendidikan, sosialisasi bahayanya pergaulan, meningkatkan kesejahteraan masyarakat, mengimplementasikan kemampuan yang dimiliki baik akademis maupun non-akademis yang akan diaplikasikan pada setiap program KKN.

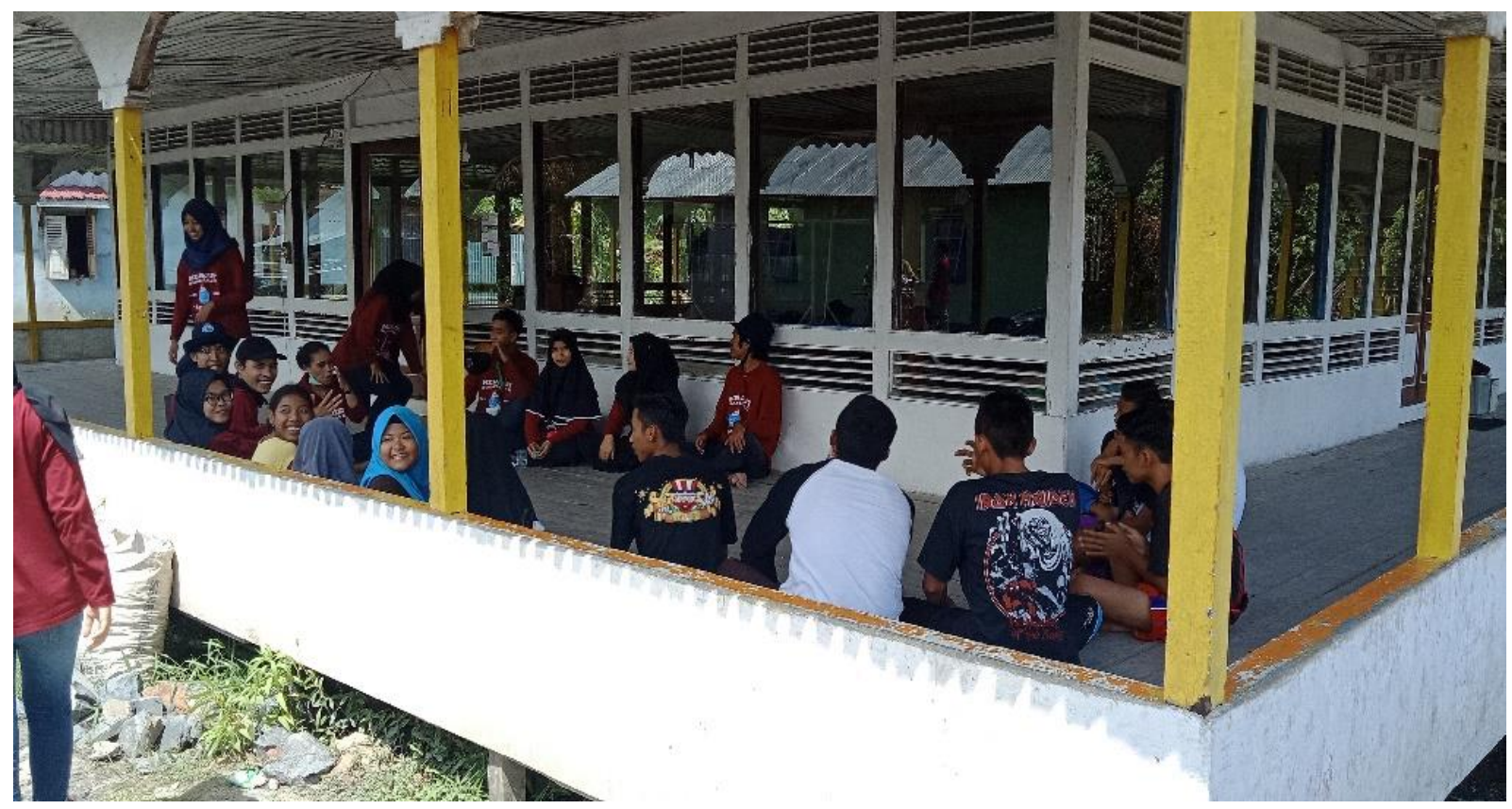

Gambar 1. Pemetaan potensi remaja Tebas Sungai dalam menjaga nilai-nilai kearifan 
Dalam pelaksanaan program kerja, waktu dan target diupayakan sesuai dengan rencana yang telah tersusun dalam daftar kegiatan. Tetapi, terdapat kemungkinan bahwa akan terjadi perbedaan antara rancangan dan pelaksanaan dikarenakan situasi dan kondisi yang tidak mendukung atau terdapat kegiatan lain yang lebih mendesak dan urgent untuk dilakukan. Pada KKN Tematik 2019, kami mengagendakan sebuah kegiatan bernuansa keagamaan, pengetahuan, dan keterampilan (kesenian local) yang siap untuk diberikan kepada remaja Desa Tebas Sungai, Kecamatan Tebas, Kabupaten Sambas, Provinsi Kalimantan Barat. Sebelum kegiatan, mula-mula kami melakukan observasi yang dilaksanakan pada tanggal 14 Maret 2019 dengan tujuan mengeksplorasi masalah dan kendala masyarakat sekitar dengan cara berdiskusi bersama kepala desa dan masyarakat sekitar. Prestasi remaja desa Tebas Sungai dapat dilihat pada Tabel 1.

Tabel 1. Perbandingan prestasi Remaja

\begin{tabular}{ccc}
\hline & Prestasi Remaja & \\
\hline Keagamaan & Pengetahuan & Keterampilan \\
\hline 8 & 17 & 6 \\
\hline
\end{tabular}

Selain mengidentifikasi masalah, di sini kami juga melangsungkan kegiatan sosial bersama masyarakat dari pagi hingga sore hari dimulai dengan memperkenalkan diri kembali serta menyampaikan maksud dan tujuan kegiatan kuliah kerja nyata. Ketika malam hari, kami mendiskusikan masalah tersebut dan petunjuk pelaksanaan bersama kelompok masingmasing dan mempersiapkan apa saja yang diperlukan untuk melangsungkan kegiatan tersebut.

Kegiatan Pendidikan sesuai dengan kelompok prestasi yang telah terbentuk berisikan program kemasyarakatan yang ditinjau berdasarkan hasil dari observasi yang telah dilakukan selama satu hari penuh Tim sampai di desa Tebas Sungai, Kecamatan Tebas tempat kami ditugaskan yang berlangsung selama 10 hari. Setelah itu, tim pendidikan melakukan observasi dengan mengunjungi lingkungan sekolah dan lingkungan masyarakat untuk mencari berbagai informasi terkait permasalahan yang ada di desa Tebas Sungai. Tim juga melakukan diskjusi dengan Karang Taruna. Atas dasar tersebut, tim dapat membuat kegiatan yang nantinya dapat membantu permasalahan-permasalahan yang ada di lingkungan masyarakat maupun lingkungan sekolah. Hal ini juga untuk memenuhi amanah sebagai mahasiswa KKN Tematik.

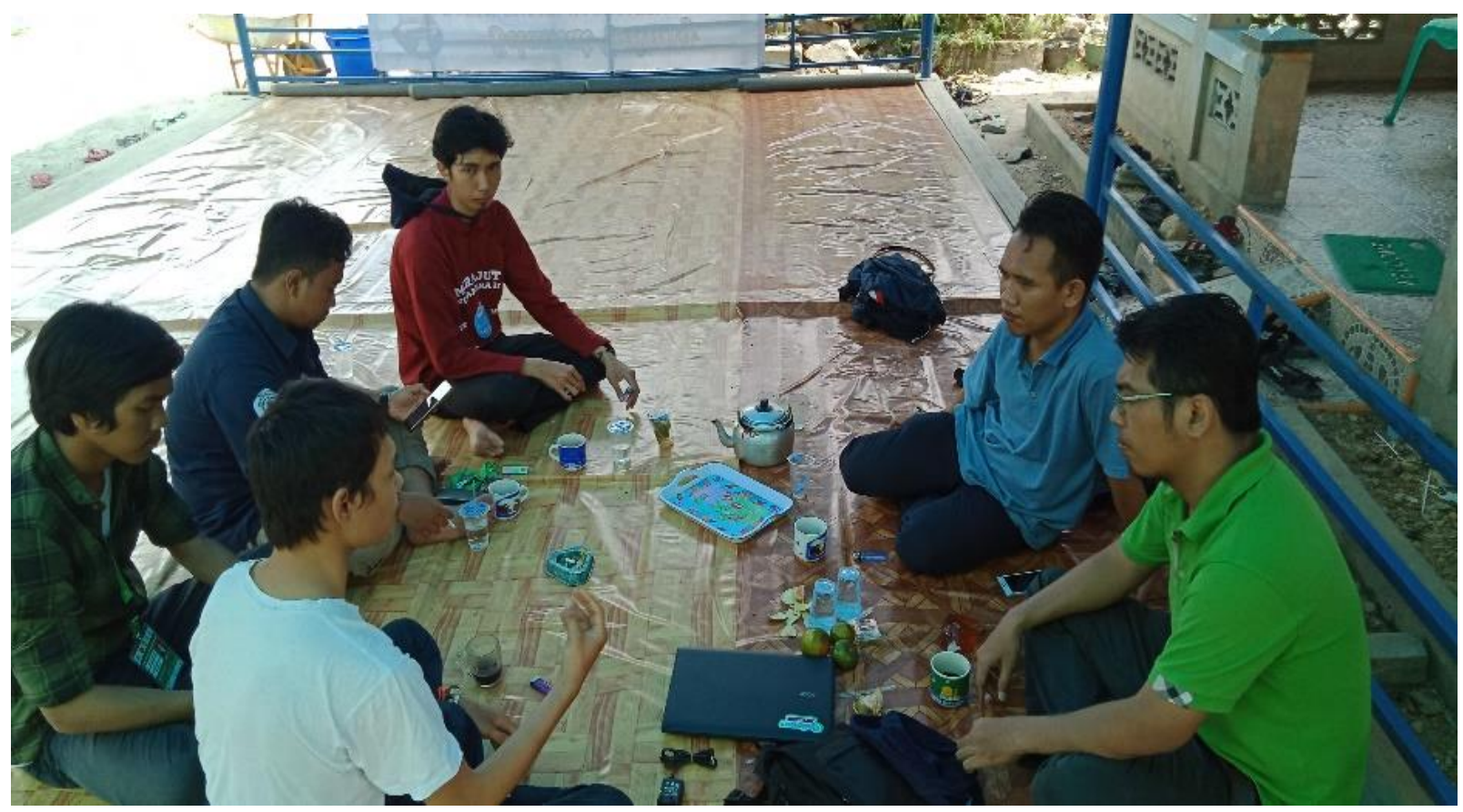

Gambar 2. Kegiatan observasi dan diskusi dengan Karang Taruna

Selain itu, kami mendiskusikan hasil observasi dan diskusi lapang bersama Dosen Pembimbing Lapangan (DPL) untuk keesokannya harinya dapat kami laksanakan kegiatan tersebut. Berdasarkan analisis situasi, identifikasi masalah, dan perencanaan program, didapatkan hasil yang telah dilaksanakan selama kegiatan Pengabdian masyarakat, maka tersusunlah beberapa program kerja dengan schedule yang telah ditetapkan.

\section{Pelaksanaan kegiatan di Desa Tebas Sungai}

Program kerja yang telah Tim laksanakan selama 10 hari terlaksana dengan lancar meskipun terdapat hambatan yang tak bisa kami hindari. Kegiatan yang telah dilakukan dapat diuraikan sebagai berikut:

\section{Pembinaan keagamaan}


Hal ini sesuai dengan data yang diperoleh bahwa mayoritas agama di Desa Tebas Sungai adalah Agama Islam. Pembinaan kegiatan lebih banyak ditempatkan di Masjid. Program yang diberikan adalah a) mengajarkan Baca Al-Qur'an dengan bantuan pengurus Masjid serta Majlis Taklim dan b) Pidato Anak agar keberanian dalam berretorika dan gestur dalam berkomunikasi dapat memberikan pesan yang menarik dan baik.

\section{Pembinaan pendidikan}

pembinaan pengetahuan selain memberikan edukasi terkait mata pelajaran dan membentuk literasi yang diajarkan oleh Tim KKN. Pembentukan Kelompok Pintar (seperti Bimbel) maka dibentuk seperti kegiatan pengajian di Masjid. Kelompok Pintar ini sudah didapat relawan dari Remaja SMA dengan pembagian Kelompok Bahasa, MIPA, dan IPS untuk nantinya akan mengajarkan kepada anak-anak pada jenjang SD-SMP. Kemudian pembuatan rak buku dan sumbangan buku cerita dan pelajaran yang bertujuan untuk meningkatkan literasi dan minat baca anak-anak Dusun.

\section{Pembinaan keterampilan}

Tim memutuskan untuk memberikan fokus lebih kepada kegiatan a) seni drama dan b) tambak ikan. Kegiatan seni drama ditampilkan karena hasil cerita masyarakat, banyak kisah yang menarik dari terbentuknya Tebas Sungai yang perlu diangkat untuk menjadikan cerita lokal menjadi cerita di sekolah dan pertunjukan tingkat Provinsi. Adapun kegiatan tambak merupakan pemetaan tim yang menilai potensi Alam dengan perpaduan sumber daya manusia perlu dimunculkan. Desa Tebas Sungai yang memiliki sungai untuk kebutuhan aktivitas sehari-hari warga. Maka Tim bersama Karang Taruna membangun "saung" dan jala apung (Gambar 3) di Sungai Tebas. Selanjutnya berdasarkan saran-saran dan antusias warga, diharapkan Desa Tebas Sungai menjadi desa Percontohan bagi desa sekitarnya.

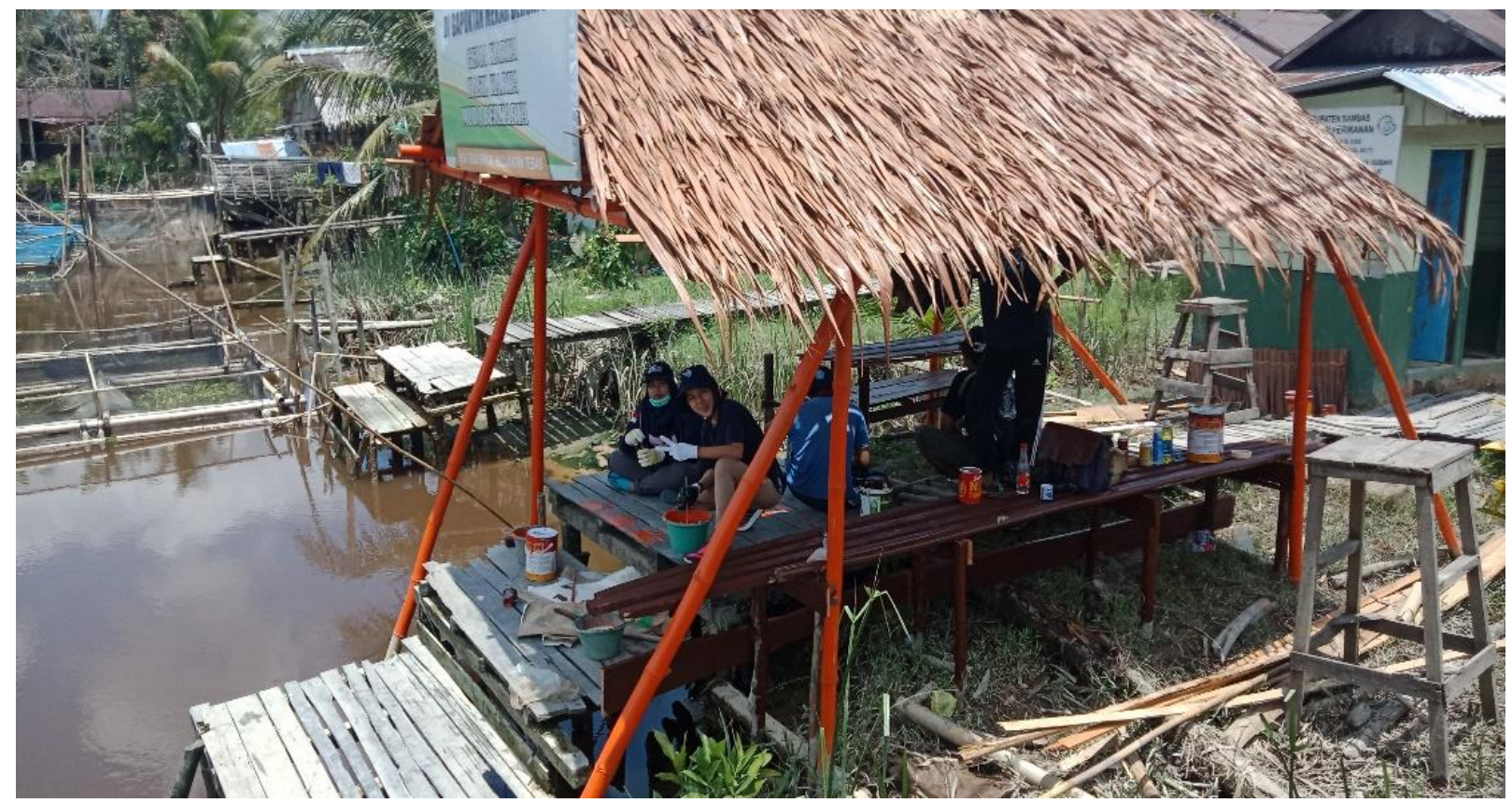

Gambar 3. Pembuatan Saung dan Jala Apung antara Tim Pengmas dengan Karang Taruna

Tugas remaja tidak hanya fokus terhadap aspek pendidikan semata tetapi sebaiknnya harus mempunyai kemampuan di bidang strategis dalam hal perencanaan dan pembentukan kelompok remaja di suatu wilayah. Karena saat ini remaja daerah dituntut harus berusaha mengembangkan berbagai kemampuan di berbagai bidang untuk dapat bersaing di era revolusi industry 4.0. Pelatihan pembinaan pada remaja pada kemampuan majemuk ini diharapkan memberikan manfaat besar bagi remaja khususnya Karang Taruna dalam melaksanakan tugasnya.

\section{KESIMPULAN}

Kegiatan pengabdian (KKN Tematik) telah terlaksana dengan baik berjalan dengan baik. Kegiatan dimulai dengan pendataan dan pemetaan, penyusunan rancangan program kerja, dan pelaksanaan kegiatan di Desa Tebas Sungai. Kegiatan inti yang dilaksanakan meliputi (1) Pembinaan keagamaan; (2) Pembinaan pendidikan; dan (3) Pembinaan keterampilan. Untuk memastikan keberlanjutan kegiatan maka saran-saran, keterlibatan, dan antusias warga Desa Tebas Sungai sangat diharapkan sehingga desa ini menjadi desa Percontohan bagi desa sekitarnya. 


\section{REFERENSI}

Arief, M. R., \& Adi, A. S. (2014). Peran karang taruna dalam pembinaan remaja di dusun candi Desa Candinegoro Kecamatan Wonoayu Kabupaten Sidoarjo. Kajian Moral Dan Kewarganegaraan, 2(1), 190-205. http://ejournal.unesa.ac.id/index.php/jurnal-pendidikan-kewarganegaraa/article/view/6700

Atik, K. M. (2019). Pelatihan Pembuatan Dan Pemanfaatan Media Pembelajaran Pada Guru Di Ppt Nur Insani Surabaya. Journal Community Development and Society, 1(2), 89-98. https://doi.org/10.25139/cds.v1i2.1810

Chen, J. J. (2005). Relation of academic support from parents, teacher, and peers to Hong Kong adolescents' academic achievement: The mediating role of academic engagament. Genetic, Social, and General Psychology Monographs, 13(2), 77-127.

Fajriah, F. (2017). Learning Journal: Improving Teaching Strategies Through Students' Reflections. Sukma: Jurnal Pendidikan, 1(2), 301-327. https://doi.org/10.32533/01204.2017

Gardner, H., \& Knoop, H. H. (2009). Good Work IN Complex Wordl. Gramedia Pustaka Utama.

Hagger, M, S., Biddle, S, J., \& Wang, C, K. (2005). Physical Self concept In Adolescence. Educational and Physhlogical Measurement, 65(2), 297-322.

Hamner, T. J., \& Turner, P. . (1990). Parenting in Contemporary Society (2nd ed.). Prentice-Hall.

Handayani, R. S., Yunus, I., Tillah, N., \& Handayani, I. (2020). Effect of Cytokines On The In Vitro of Sweet Kaffir Lime (Citrus hystrix Dc). Journal of Tropical Horticulture, 3(2), 60. https://doi.org/10.33089/jthort.v3i2.51

Hatimah, I. (2003). Pengertian Pendekatan, Strategi, Metode, dan Teknik Pembelajaran. http://file.upi.edu/Direktori/FIP/JUR._PEND._LUAR_SEKOLAH/195404021980112001IHAT_HATIMAH/Pengertian_Pendekatan,_strategi,_metode,_teknik,_taktik_dan.pdf

Henderson, C, E., Dakof, G, A., Schwartz, S, J., \& Lidle, H, A. (2006). Family fuctioning, Self Concept and severaty adolescance externalizing problems. Journal Child, Family Study, 15, 721-731.

Maghfiroh, N., Susilo, H., \& Gofur, A. (2016). Kemampuan berpikir kreatif siswa kelas x sma negeri 4 sidoarjo pada mata pelajaran biologi. Seminar Nasional Pendidikan Dan Saintek 2016, 2016(2), 635-639.

Marsh, H. W., Boivin, M., \& Guay, F. (2003). Academic Self Concept and Academic Achievement: Developmental Perspectives on Their Causal Ordering. Journal of Educational Psychology, 95(1), 124-136.

https://doi.org/10.1037/0022-0663-95-1-124.

Mulyasa, E. (2002). Manajemen Berbasis Sekolah. PT. Remaja Rosdakarya.

Papalia, D. . (2004). Human Development (9th ed.). Mc Graw Hill.

Pratama, F. F., Indonesia, U. P., \& Indonesia, B. (2018). Jurnal Civics : Media Kajian Kewarganegaraan. 15(2).

Sari, R., Massawet, E. T., \& Masruhim, M. A. (2018). Perangkat Pembelajaran Kecerdasan Eksistensial dan Keterampilan Berpikir Kreatif Siswa dalam Pembelajaran Biologi. 1068-1075.

Susana. (2006). Konsep Diri Positif Menentukan Prestasi Anak. Kanisius. 